\title{
Evaluation of Bond Strength Between Carbon Fiber Reinforced Polymer (CFRP) Composites with Modified Epoxy Resins and Concrete
}

\author{
Mohamed H. Rabie \\ m.rabie@qu.edu.qa \\ Department of Civil and Architectural Engineering, Qatar University, Doha, Qatar \\ Eman M. Fayyad \\ emfayad@qu.edu.qa \\ Center for Advanced Materials, Qatar University, Doha, Qatar
}

Mohammad R. Irshidat

mirshidat@qu.edu.qa

Center for Advanced Materials, Qatar University, Doha, Qatar

Nasser A. Alnuaimi

anasser@qu.edu.qa

Department of Civil and Architectural Engineering / Center for Advanced Materials, Qatar University, Doha, Qatar

\author{
Mohammad K. Hassan \\ mohamed.hassan@qu.edu.qa \\ Department of Civil and Architectural Engineering, Qatar University, Doha, Qatar
}

\begin{abstract}
Rehabilitation and strengthening of concrete structures are becoming more significant in civil engineering applications. The use of externally bonded Fiber Reinforced Polymers (FRP) is one of the methods to strengthen and rehabilitate reinforced concrete members, providing noticeable improvement to their capacity in resisting load. Carbon Fiber Reinforced Polymer (CFRP) is used along with epoxy resins to evaluate the bond strength of two commercially available epoxies (EPON 828 and EPON 862) between CFRP and concrete. In addition, three new combinations that resulted from mixing the two epoxies were examined. The mechanical properties of epoxy resins are significantly weaker than this of the CFRP making the epoxy characteristics the determining factor in the quality of the bond strength. Three-point flexural test was conducted to examine the bond strength between the CFRP composites and concrete. Further, differential scanning calorimetry was conducted to examine the glass transition temperature of the resultant epoxies. The results showed that the optimum composition was a mixture of $70 \%$ of epoxy 828 and $30 \%$ of epoxy 862 . Therefore, achieving better bond strength and high glass transition temperature, resulting in CFRP composite with higher fire resistance.
\end{abstract}

Keywords: CFRP; Epoxy composition; Bond strength; Concrete

\section{INTRODUCTION}

Recently, the need to develop the economic and efficient methods to strengthen the reinforced concrete has received considerable attention. The use of Carbon Fiber Reinforced Polymer (CFRP) composites to increase the rigidity of the concrete structure against the harsh environment was identified as a possible alternative to other strengthening methods (Issa \& Asce, 2004). The alternative methods such as adding 
of unstressed or pre-stressed steel, installation of external pre-stressed reinforcement, increasing cross-sections are expensive and not enough efficient. Nevertheless, addition of CFRP materials do not corrode because they are a combination of carbon fibers and an epoxy resin matrix that have very high strength and rigidity in the fiber direction and outstanding fatigue characteristics.

Epoxy resins are thermosetting polymers, which are cross-linked using hardeners (curing agents). The most common curing agents for epoxy resins are polyamines, amino amides, and phenolic compounds (Forrest, 2005).

Generally, significant advances characterize the epoxy like excellent adhesion, good strength, low shrinkage, good corrosion resistance, resistance to moisture, thermal and mechanical shock and processing versatility (Zhipeng et al., 2014). Therefore, they are used in many applications as encapsulating materials, adhesive, high performance coatings and so many applications. Several types of epoxy resins are present based on their weight per epoxide and viscosity. Epoxy 828 has viscosity range from 110-150 $\mathrm{P}$ at $25^{\circ} \mathrm{C}$ and $185-192$ weight per epoxide whereas epoxy 862 is characterized by lower viscosity, 25-45 $\mathrm{P}$ at $25^{\circ} \mathrm{C}$ and lower weight per epoxide, 165-173.

The present study investigates the adhesion of five different epoxy compositions through three-point flexural test. Epoxy 828 and epoxy 862 commercially available were used to produce three different mixtures of epoxies with variable percentages. Differential Scanning Calorimetry (DSC) was conducted to evaluate the glass transition temperature of five epoxy compositions.

\section{MATERIALS AND METHODS}

\subsection{Materials}

A total of ten concrete prisms divided into two patches were prepared using readymixed concrete. The mix design per cubic meter used to prepare the concrete prisms is composed of $831 \mathrm{Kg}$ of sand, $693 \mathrm{Kg}$ of course aggregate, $455 \mathrm{Kg}$ of fine aggregate, $340 \mathrm{Kg}$ Portland cement and w/c ratio of 0.47 . Compression test was performed on two concrete cylinders with a dimension of $100 \times 300 \mathrm{~mm}$ in accordance with ASTM C39. The average 28-day compressive strength is equal $43 \mathrm{MPa}$.

Commercial Carbon Fiber (CF) sheets purchased from SIKA group were placed in the tension side of the concrete prisms. Furthermore, a total of five compositions of Epoxy resins were prepared. Two of them were commercially available as Bisphenol A (Epon 828) and Bisphenol F (Epon 826) and diethylenetriamine as a hardener. The remaining three were prepared by mixing Bisphenol A (Epon 828) and bisphenol F (Epon 826) using different ratios. Table 1 summarizes the percentage used to prepare the five epoxy samples.

Table 1: Epoxy compositions

\begin{tabular}{|c|c|c|c|}
\hline Sample number & Sample code & Epon 828 (\%) & Epon 862 (\%) \\
\hline 1 & BISA & 100 & 0 \\
\hline 2 & $70 \mathrm{~A} / 30 \mathrm{~F}$ & 70 & 30 \\
\hline 3 & $50 \mathrm{~A} / 50 \mathrm{~F}$ & 50 & 50 \\
\hline 4 & $30 \mathrm{~A} / 70 \mathrm{~F}$ & 30 & 70 \\
\hline 5 & $\mathrm{BISF}$ & 0 & 100 \\
\hline
\end{tabular}




\subsection{Experimental program}

\subsubsection{Bond strength}

Ten concrete prisms were prepared with geometry shown in Figure 1a. All concrete prisms were of a length of $50 \mathrm{~cm}$ with a rectangular cross section of $10 \mathrm{~cm}$ x $10 \mathrm{~cm}$. A saw cut with a depth of $2.5 \mathrm{~cm}$ was made at the center of the concrete prism to allow for using three-point bending loading scheme (Tatar \& Hamilton, 2016). The CFRP sheets were applied in the tension side of the concrete prism. The dimensions of the CFRP are $\mathrm{L} \times \mathrm{W}=20 \times 2.5 \mathrm{~cm}$ as shown in Figure 1d.

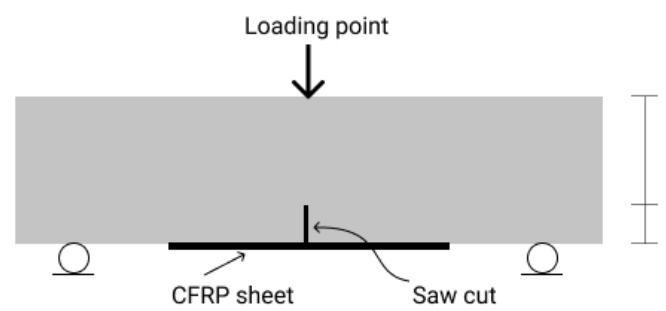

(a)

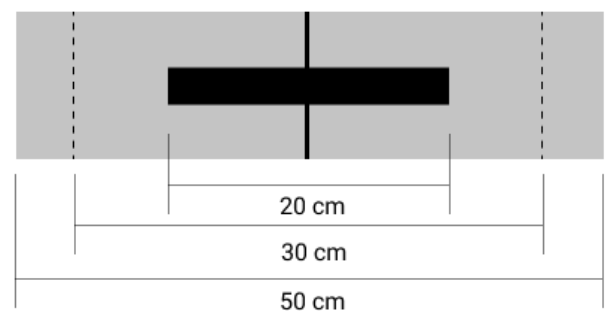

(c)

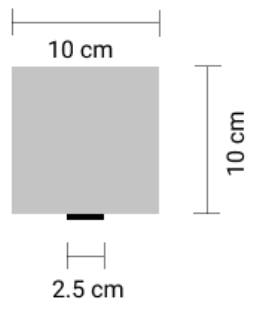

(b)

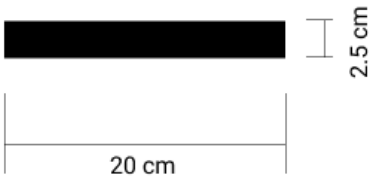

(d)

Figure 1: Concrete prism dimensions: a) side view, b) cross section, c) bottom view, d) CF sheet

\subsubsection{Differential scanning calorimetry}

Measurements of differential scanning calorimetry are carried out using DSC 8500 by Perkin Elmer. DSC is used to examine many epoxy adhesion properties such as initial and final glass transition temperatures, heat curing, and the final material's specific heat. $10{ }^{\circ} \mathrm{C} / \mathrm{min}$ as a heating rate was used on temperature range from 20 to $150{ }^{\circ} \mathrm{C}$. (McKeen, 2014).

\section{RESULTS AND DISCUSSION}

\subsection{Bond strength}

Flexural test was performed on ten concrete prisms as detailed in the aforementioned section. The results are summarized in Table 2 . The result showed that the maximum load was resisted by Bisphenol F (BISF) with an average load of $16.39 \mathrm{kN}$. Sample four ranked second in resisting the load applied to the concrete prisms with an average load of $16.28 \mathrm{kN}$. These results indicate the bond strength between the CFRP and the concrete prism. The higher the load resisted the stronger the bond between CFRP and the concrete prism. Figure 2 and Figure 3 show the set-up of the testing machine and the load vs. 
displacement curves for the sample of the tested specimens.

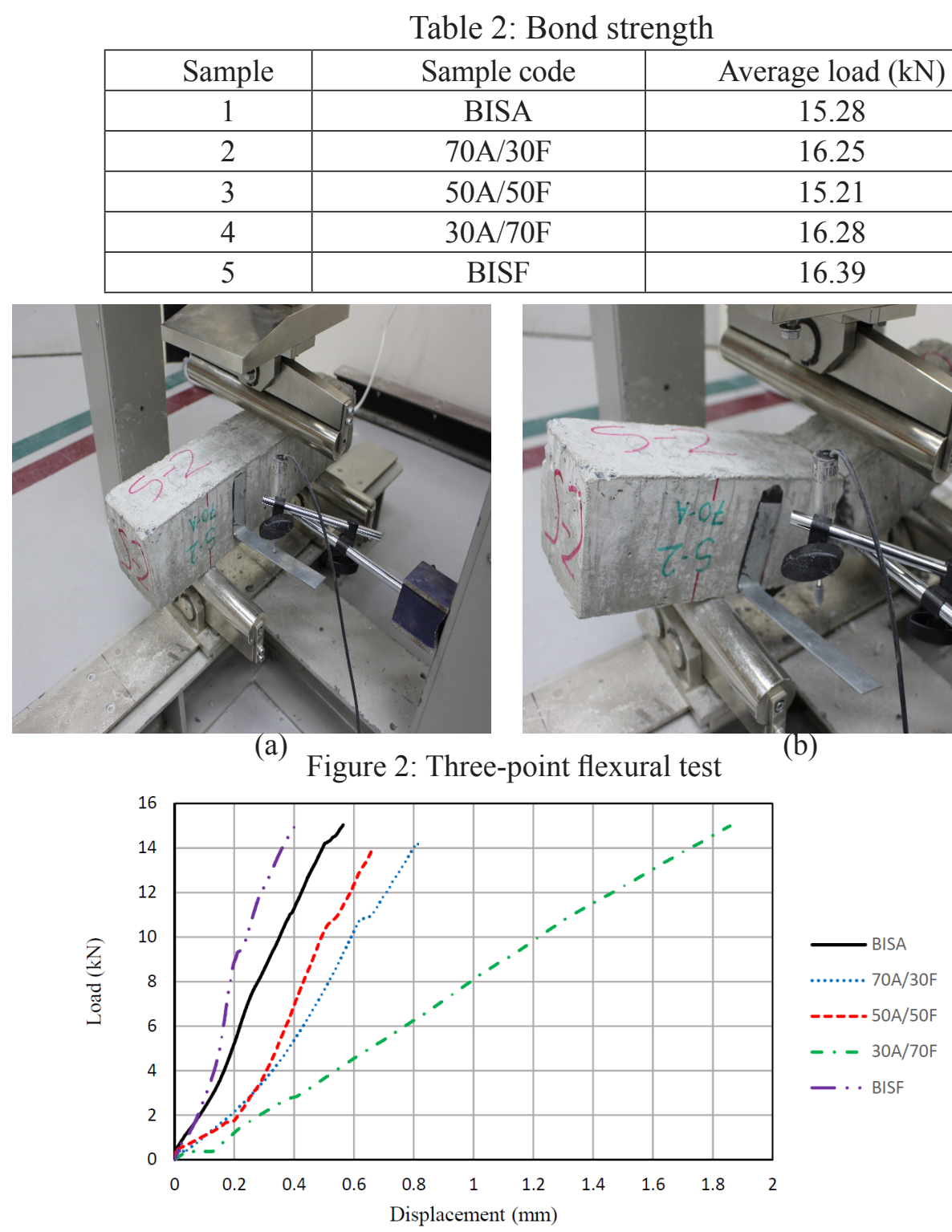

Figure 3: Load vs. displacement

\subsection{Differential scanning calorimetry}

Figure 4 shows the DSC heat-cool-heat of the different five compositions of CFRP samples at a heating rate of $10{ }^{\circ} \mathrm{C} / \mathrm{min}$ during temperatures range from 20 to $150{ }^{\circ} \mathrm{C}$. DSC was utilized to determine the glass transition temperature $(\mathrm{Tg})$, which ranged from 104 to $130{ }^{\circ} \mathrm{C}$ in the heating curve, as shown in Figure 4 and ranged from $110-130{ }^{\circ} \mathrm{C}$ in the cooling curve. $\mathrm{Tg}$ is the temperature where the epoxy adhesive transitions from a glassy hard material to a rubbery soft material (Al-Tamimi et al., 2014). It is documented that the extreme environmental temperatures affect the durability of the bond strength 
between externally bond CFRP plates and the concrete prism (Abbas, 2010). As the temperatures close to the transition temperature ( $\mathrm{Tg}$ ) of CFRP, the durability of their bond strength diminishes (Gamage, Wong, and Al-Mahadi, 2005).

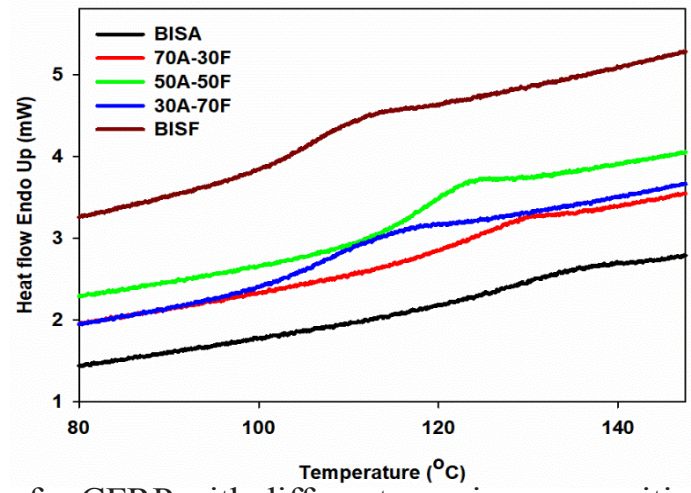

Figure 4: DSC curves for CFRP with different epoxies compositions Tg in the heating curves

It is observed that DSC curve of BISA shows a glass transition around $130{ }^{\circ} \mathrm{C}$, which is the highest $\mathrm{Tg}$ value whereas the BISF possessed the smallest one compared to all the used compositions, as shown in Figure 4. The DSC results are summarized in Table 3. The different compositions of BISA and BISF $[70 \mathrm{~A} / 30 \mathrm{~F}, 50 \mathrm{~A} / 50 \mathrm{~F}$ and $30 \mathrm{~A} / 70 \mathrm{~F}]$ possessed $\mathrm{Tg}$ of 122,117 and $108{ }^{\circ} \mathrm{C}$, respectively. As expected, adding of BISF to BISA results in CFRP networks with lower Tg compared to the use of BISA only. However, all different composition still have high Tg value compared to other composites. In addition, the $70 \mathrm{~A} / 30 \mathrm{~F}$ composition shows higher $\mathrm{Tg}$ value than the other two compositions, $50 \mathrm{~A} / 50 \mathrm{~F}$ and $30 \mathrm{~A} / 70 \mathrm{~F}$. This indicates the well cross-linked of 70A/30F epoxy composition with the carbon fiber since it has a higher crosslink density.

Table 3 DSC summary results

\begin{tabular}{|l|l|l|l|l|l|}
\hline Sample code & Area $(\mathrm{mJ})$ & $\Delta \mathrm{H}(\mathrm{J} / \mathrm{g})$ & Peak & $\Delta \mathrm{C}_{\mathrm{p}} \mathrm{J} / \mathrm{g}{ }^{\circ} \mathrm{C}$ & $\begin{array}{l}\mathrm{T}_{\mathrm{g}} \\
\left({ }^{\circ} \mathrm{C}\right)\end{array}$ \\
\hline BISA & 72.933 & 8.8404 & 57.07 & 0.161 & 130.45 \\
\hline $70 \mathrm{~A} / 30 \mathrm{~F}$ & 66.910 & 9.0175 & 57.94 & 0.197 & 122.48 \\
\hline $50 \mathrm{~A} / 50 \mathrm{~F}$ & 75.697 & 7.9098 & 57.47 & 0.351 & 117.36 \\
\hline $30 \mathrm{~A} / 70 \mathrm{~F}$ & 77.604 & 10.0135 & 57.52 & 0.319 & 108.05 \\
\hline BISF & 237.051 & 27.596 & 58.37 & 0.386 & 104.99 \\
\hline
\end{tabular}

\section{CONCLUSION}

The bond strength between CFRP laminate and the concrete was evaluated using three-point bending test for total of five epoxy compositions. Further investigation of the glass transition temperature epoxy compositions was evaluated using DSC and the following conclusions were highlighted:

- Epoxy composition BIS A owned glass transition temperature higher than that of Epoxy composition BIS F. In the case of resin made of a mixture of the two types of epoxy, the 70A/30F composition shows higher Tg value. 
- Epoxy composition BIS A resin has a melting temperature of $57^{\circ} \mathrm{C}$. Replacing Epoxy BIS A with Epoxy BIS F in different percentages (30, 50 and $70 \%$ ) leads to increase in the crystallization melting temperature of the hard chains of CFRP composites.

- The new epoxy compositions slightly affected the bond strength between CFRP composites and concrete.

Future research might study the temperature as a factor affecting the epoxy properties.

\section{REFERENCES}

Abbas, Basim M Mahdi (2010). Durability of CFRP-concrete bond under sustained load in harsh environment. Civil Engineering, MONASH University.

Al-Tamimi, Adil K., Rami A. Hawileh, Jamal A. Abdalla, Hayder A. Rasheed \& Riadh AlMahaidi (2014). Durability of the bond between CFRP plates and concrete exposed to harsh environments. Journal of Materials in Civil Engineering, 27 (9): 04014252. https://doi. org/10.1061/(asce)mt.1943-5533.0001226.

Forrest, M. J. (2005). Coatings and Inks for Food Contact Materials. iSmithers, Rapra Publishing.

Gamage, J. C. P. H., Wong, M. B. \& Al-Mahadi, R. (2005). Performance of CFRP strengthened concrete members under elevated temperatures. Proceeding of the International Sysposium on Bond Behaviour of FRP in Structures (BBFS 2005), No. Bbfs: 113-18.

Issa, Camille A. \& Asce, F. (2004). Carbon fiber reinforced polymer strengthening of reinforced concrete beams : experimental study, 10 (December): 121-25.

McKeen, Laurence W. (2014). Introduction to the effect of heat aging on plastics. The Effect of Long Term Thermal Exposure on Plastics and Elastomers, 17-42. https://doi.org/10.1016/ b978-0-323-22108-5.00002-3.

Tatar, J. \& Hamilton, H. R. (2016). Comparison of laboratory and field environmental conditioning on FRP-concrete bond durability. Construction and Building Materials, 122: 525-36. https:// doi.org/10.1016/j.conbuildmat.2016.06.074.

Zhipeng He, Yue Wang, Tingting Zhao, Zichuan Ye, He Huang (2014). Ultrasonication-assisted rapid determination of epoxide value in polymer mixtures containing epoxy resin. Analytical Methods, 6(12): 4257-61. 